\title{
Effect of Mineralogical Phase and Chemical Composition of Fly Ash on Electromagnetic Wave-Absorbing Properties
}

\author{
Yinsuo Dai ${ }^{1,2}$, Jianhua $\mathrm{Wu}^{1, *}$, Derong Wang ${ }^{1}$, Chunhua $\mathrm{Lu}^{2}$ and Zhongzi $\mathrm{Xu}^{2}$ \\ ${ }^{1}$ National Defense Engineering College, Army Engineering University of PLA, Nanjing 210007, China \\ ${ }^{2}$ College of Materials Science and Engineering, Nanjing Tech University, Nanjing 210009, China
}

\begin{abstract}
In order to explore the electromagnetic radiation protection function of fly ash as building materials, Scanning Electron Microscope (SEM), X-ray diffraction (XRD), X-ray photoelectron spectroscopy (XPS) and Mössbauer were used to analyze the chemical composition and mineralogical phase of two types of fly ash. Electromagnetic parameters of the samples were analyzed and discussed in detail at the frequency range of $1 \sim 18 \mathrm{GHz}$. The results showed that fly ash had electromagnetic wave absorbing property due to porous carbon grain and iron oxide, and that dielectric loss was more than magnetic loss for fly ash and electromagnetic property of type III was more than of type I. There were several absorbing-wave interference peaks at the frequency of $1-18 \mathrm{GHz}$, at thickness of $10-20 \mathrm{~mm}$ epoxy-based fly ash. The cement-based fly ash showed electromagnetic wave-absorbing properties at $10 \sim 18 \mathrm{GHz}$ and the biggest absorption reached $14.5 \mathrm{~dB}$ at $16 \mathrm{GHz}$ at the thickness of $20 \mathrm{~mm}$, so the fly ash should be expected to be a building material for electromagnetic protection. [doi:10.2320/matertrans.M2017378]
\end{abstract}

(Received December 6, 2017; Accepted March 12, 2018; Published May 25, 2018)

Keywords: fly ash, mineralogical phase, chemical composition, electromagnetic parameters, absorbing wave properties

\section{Introduction}

Fly ash is the main waste residue produced in thermal power station. Every year, millions tons of fly ash are generated all over the world and have caused great pollution. Annual interest use rate is only $40 \%$. The major compositions of fly ash are $\mathrm{SiO}_{2}, \mathrm{Al}_{2} \mathrm{O}_{3}$ and $\mathrm{Fe}_{2} \mathrm{O}_{3}$, and their amount take the around $85 \%$ of fly ash. The representative component content of carbon is over $5 \%$ for $61 \%$ plants, and statistical results of 40 large-scale thermal power plants in China are listed in Table 1. ${ }^{1)}$

Fly ash has the pozolonic reactivity so that it can be used widely as a supplementary cementing material in concrete. Further possible utilization requires a detailed knowledge of their morphology, chemical and mineralogical composition. The chemical composition and structure of fly ash particles can influence the electromagnetic properties. ${ }^{2-5}$ )

The chemical composition of unburned carbon is basically identical: $73-91 \%$ carbon, 5-19\% ash $\left(\mathrm{Fe}_{2} \mathrm{O}_{3}\right.$ in ash reaches $28 \%-30 \%), 2.5-11.5 \%$ volatile substances, and $0.7-1.9 \%$ water, which consists of porous spherical particles and some crumbled particles; and most of them are hollow, porous structure, or layer structure by SEM. ${ }^{6}$ The experimental results showed that the unburned carbon in fly ash exhibited the frequency characteristics of microwave attenuation because of bipolar, multi-reflections. ${ }^{7,8}$ ) The main mineralogical phases of fly ash are quartz, mullite, magnetite $\left(\mathrm{Fe}_{3} \mathrm{O}_{4}\right)$, hematite $\left(\mathrm{Fe}_{2} \mathrm{O}_{3}\right)$, other oxides and glassy compound such as silica glass, and the minor mineralogical phase are magnetite. In China, the average content of $\mathrm{Fe}_{2} \mathrm{O}_{3}$ in fly ash from 40 large-scale thermal power plants is $50-100 \mathrm{~g} / \mathrm{Kg} .{ }^{9}$

\section{Materials and Experimental Methods}

In order to compare the effect of particle size on properties, type III and type I fly ash were chosen. Type III fly ash was grey-black, supplied by the Nanjing Second Thermal Power

*Corresponding author, E-mail: wjh87@hotmail.com
Table 1 Mineralogical component of fly ash in China.

\begin{tabular}{ccccccc} 
& & & & & \multicolumn{2}{c}{$/$ mass \% } \\
\hline Mullite & H-glassy pellet & L-glassy pellet & $\mathrm{C}$ & $\mathrm{SiO}_{2}$ & $\mathrm{Al}_{2} \mathrm{O}_{3}$ & $\mathrm{Fe}_{2} \mathrm{O}_{3}$ \\
\hline $11.3 \sim 29.2$ & $0 \sim 21.1$ & $42.2 \sim 70.1$ & $1.0 \sim 23.5$ & $33.9 \sim 59.7$ & $16.5 \sim 35.1$ & $1.5 \sim 19.7$ \\
\hline
\end{tabular}

${ }^{*} \mathrm{H}$ : high-iron; L: low-iron. (a)

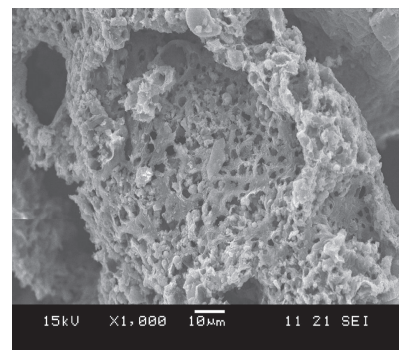

(b)

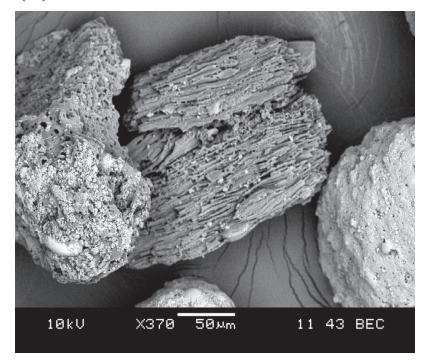

Fig. 1 SEM image of fly ash from Nanjing second power plant. (a) Irregular porous particles. (b) Layer char of unburned carbon particles.

Station and at least $32.8 \%$ passed through $45 \mu \mathrm{m}$ mesh. Type I fly ash was light grey-black, supplied by the Nanjing Huaneng Thermal Power Station and at least $92.8 \%$ passed through $45 \mu \mathrm{m}$ mesh. P.O 42.5 cement was produced by China Cement Company.

Morphology of fly ash from Nanjing second power plant by Scanning Electron Microscope at $15 \mathrm{kV}$ (SEM) (JEOL, JSM-5900, Japan) were shown in Fig. 1, which suggested that there were plenty of macrospore in the unburned carbon and other particles.

Fly ash was packed as densely as possible into the sample holder (depth was $0.5 \mathrm{~mm}$ ) for XRD (Japan Rigaku Corporation, D/Max-rB) and scans were taken from 5 to $80^{\circ}$ $2 \theta$ at a scanning rate of $10^{\circ} 2 \theta / \mathrm{min}$ with a step of size of $0.02^{\circ} 2 \theta$.

$\mathrm{X}$-ray photoelectron spectroscopy (XPS) is regarded as electron spectroscopy for chemical analysis (ESCA). XPS survey spectra are used to verify alpha-hematite phase. The stoichiometry of them is precisely controlled by in situ XPS 
analysis. XPS of fly ash were tested on XR5 Gun-500 $\mu \mathrm{m}$ $(\mathrm{Al} \mathrm{K} \alpha, 15 \mathrm{kV}-150 \mathrm{~W}$ ) in Hefei National Laboratory for Physical Sciences at the Microscale, University of Science and Technology of China. The C1s spectra were used as standards for the calibration of non-conductive samples. The spectrometer was operated at a pressure of $2 \times 10^{-7} \mathrm{~Pa}$ and the resolution of survey spectra was $1 \mathrm{eV}$.

${ }^{57} \mathrm{Fe}$ Mössbauer spectroscopy has several manifest advantages, such as $100 \%$ selectivity for iron, without interference from other elements of monocrystals, polycrystalline and amorphous materials, and also of "in situ" studies. It can be used for determining the $\mathrm{Fe}^{2+} / \mathrm{Fe}^{3+}$ ratio in hematite because Fe-bearing mineralogical phase play an important role in absorbing-wave materials. The mineralogical phase of fly ash were measured by a Mössbauer spectrometer instrument type VIS-1170-MO and ${ }^{57} \mathrm{Co}(\mathrm{Pd})$ source with $25 \mathrm{mCi}$ activity, in constant acceleration, at room temperature $(293 \mathrm{~K})$, at equal velocity scale. The spectra were calibrated using a $\alpha$-Fe foil and the experimental data were ananylized by MossWinn3.0.

Electromagnetic parameters of round ring sample (thickness was $2.0 \mathrm{~mm}$ and outer/inner diameter was $7.0 / 3.0 \mathrm{~mm}$ ) were tested at the frequency of $1-18 \mathrm{GHz}$ in Nanjing University by the waveguide method of round coaxial and fly ash was used in the proportions by weight relative to oxygen resin, namely, 60:40.

Reflectivity were evaluated by the arch method using an HP8722ET vector network analyzer and standard horn antennas in an anechoic chamber according to GJB203894. ${ }^{10)}$ The sizes of samples were $180 \mathrm{~mm} \times 180 \mathrm{~mm}$ at the thickness of $10 \mathrm{~mm}, 20 \mathrm{~mm}$. The absorbing-wave properties of fly ash were tested by weight proportion as: fly ash:epoxy:polymerizer $=1.5: 1: 1$. The addition of Type III fly ash was nearly $10 \%$ because of low activity in hydrated
Table 2 Weight proportion of samples.

\begin{tabular}{ccccc}
\hline & Cement & Sand & Water & Fly ash (content) \\
\hline Hydrated cement & 1 & 0 & 0.29 & $0.15(13 \%)$ \\
Mortar & 1 & 3 & 0.5 & $0.45(10 \%)$ \\
\hline
\end{tabular}

cement and the weight proportion of hydrated cement with fly ash were listed in Table 2.

\section{Results and Discussion}

\subsection{Chemical components}

Chemical compositions of fly ash and cement samples analyzed by XRF (Rigaku 3063) were shown in Table 3; especially the content of carbon was analyzed by Carbon/ sulphur Detector (JTY-CS206) in Nanjing University.

\subsection{X-ray diffraction analysis}

The results of XRD analysis were shown in Fig. 2. All sharp peaks can be identified to either quartz $\left(\mathrm{SiO}_{2}\right)$ or mullite $\left(3 \mathrm{Al}_{2} \mathrm{O}_{3} \cdot 2 \mathrm{SiO}_{2}\right)$. The broad diffraction peak indicated the presence of amorphous (glassy) phase in fly ash sample. These data show that despite the complex composition, the fly ash always contains separable glass, quartz-mullite, and $\mathrm{Fe}$ spinel $\left(\mathrm{Fe}_{2} \mathrm{O}_{3}, \mathrm{Fe}_{3} \mathrm{O}_{4}\right)$. The fly ash is enriched in magnetite-hematite which has potential applications such as absorbing electromagnetic wave.

\subsection{X-ray photoelectron spectroscopy analysis}

Figure 3 revealed that $\mathrm{O}, \mathrm{Si}, \mathrm{Ca}, \mathrm{Al}, \mathrm{Fe}$ can be identified on the samples. The amount ratio of several main peaks were shown in Table 4 which were consistent with the results in Table 3 .

Table 3 Chemical component of materials

\begin{tabular}{ccccccccc} 
& \multicolumn{1}{c}{} & \multicolumn{5}{c}{$/ \mathbf{m a s s} \%$} \\
\hline & $\mathrm{SiO}_{2}$ & $\mathrm{Al}_{2} \mathrm{O}$ & $\mathrm{CaO}$ & $\mathrm{MgO}$ & $\mathrm{SO}_{3}$ & $\mathrm{Fe}_{2} \mathrm{O}$ & LOI & $\mathrm{C}$ \\
\hline Nanjing second power plant & 46.22 & 28.24 & 3.63 & 0.74 & - & 2.81 & 13.0 & 5.12 \\
Huaneng power plant & 54.7 & 28.98 & 4.48 & 0.56 & 0.58 & 5.24 & 2.24 & 1.11 \\
Cement & 22.60 & 5.03 & 63.11 & 1.46 & 2.24 & 4.38 & 1.18 & - \\
\hline
\end{tabular}

(1)

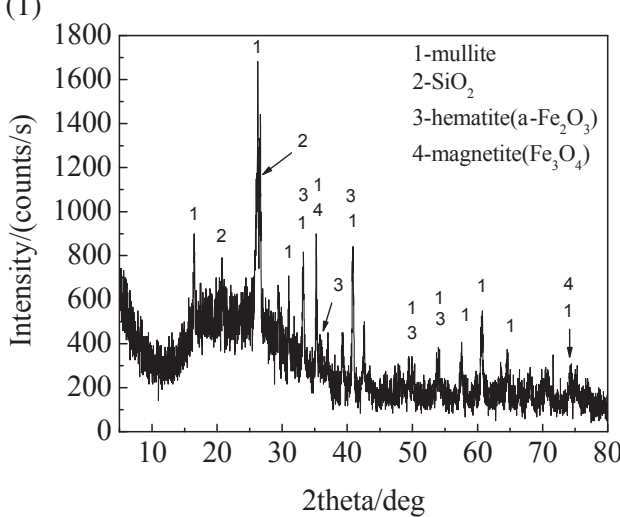

(2)

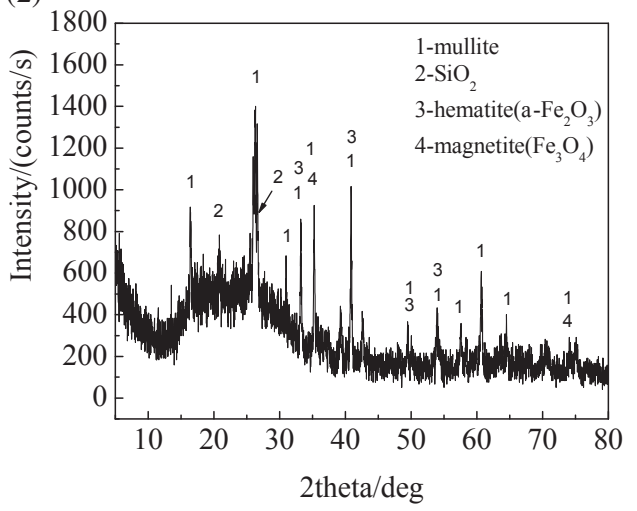

Fig. 2 X-ray diffraction pattern of the fly ash. (1) Nanjing second power plant. (2) Huaneng power plant. 
(1)

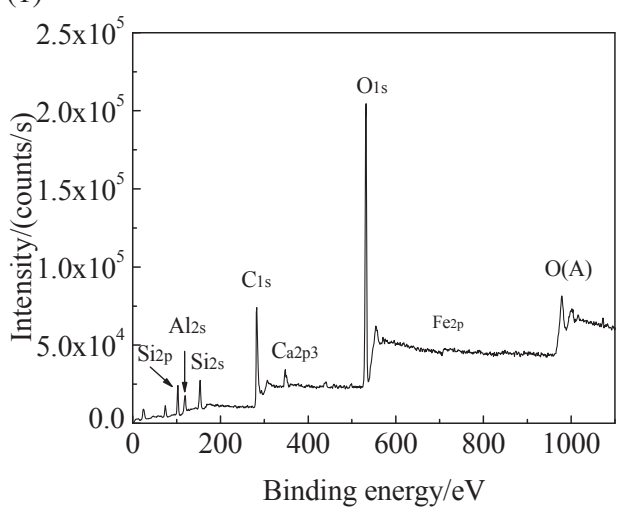

(2)

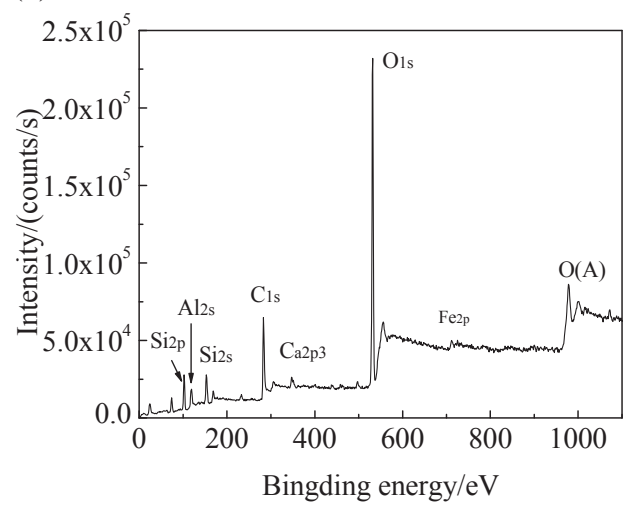

Fig. 3 XPS survey spectra of fly ash surface. (1) Nanjing second power plant. (2) Huaneng power plant.

Table 4 Quantitative analysis of several main peaks.

\begin{tabular}{ccccccc}
\hline & \multicolumn{2}{c}{ Nanjing second power plant } & \multicolumn{3}{c}{ Huaneng power plant } \\
\cline { 2 - 6 } & Peak BE /eV & FWHM /eV & At. \% & Peak BE /eV & FWHM /eV & At. \% \\
\hline C1s & 282.56 & 2.13 & 46.33 & 282.76 & 1.08 & 35.64 \\
O1s & 531.70 & 2.83 & 52.65 & 531.66 & 2.64 & 62.99 \\
Fe2p & 711.84 & 5.09 & 1.02 & 711.59 & 4.91 & 1.38 \\
\hline
\end{tabular}

(1)

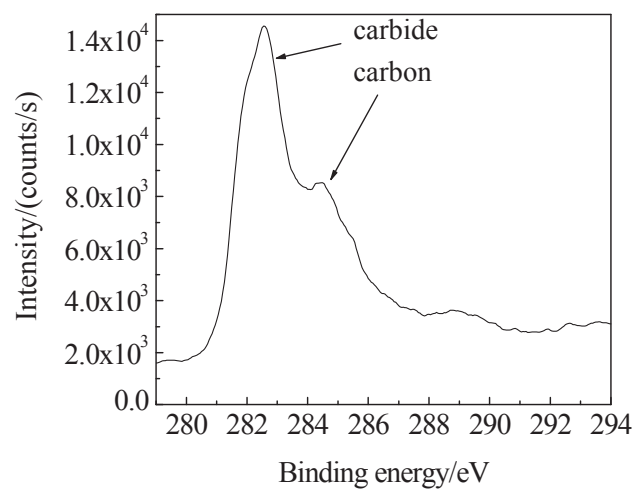

(2)

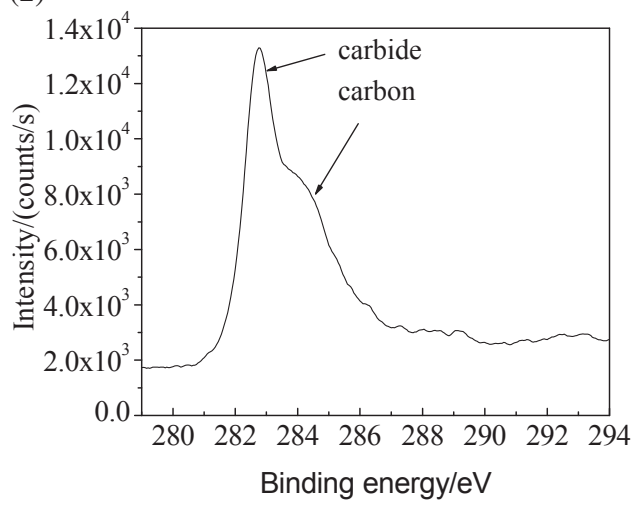

Fig. 4 XPS spectra of carbon element on fly ash surface. (1) Nanjing second power plant. (2) Huaneng power plant.

(1)

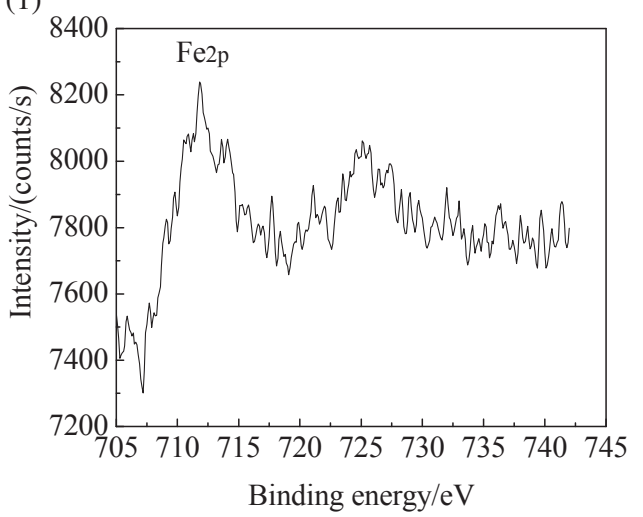

(2)

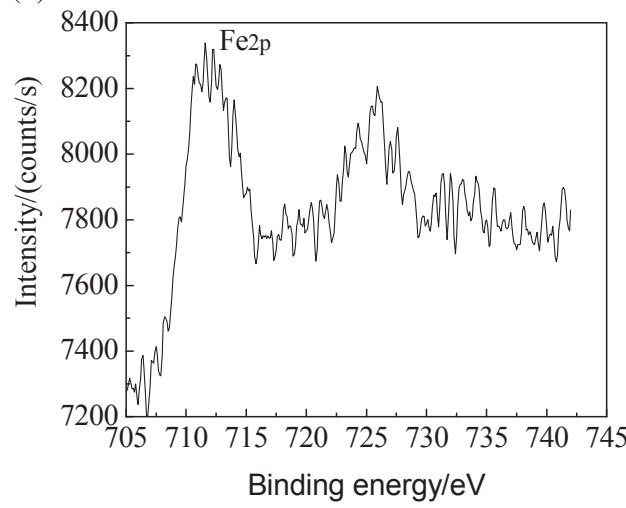

Fig. 5 XPS spectra of iron element on fly ash surface. (1) Nanjing second power plant. (2) Huaneng power plant.

The surface properties of the carbons were analyzed by using XPS as shown in Fig. 4. As seen the binding energies were centered at $282.5 \mathrm{eV}$ and $284.4 \mathrm{eV}$ which can be attributed to carbide and carbon respectively and indicated a notable disassociation in the spectra. ${ }^{11)}$
Figure 5 indicated the presence of $\mathrm{Fe}$ and $\mathrm{Fe}$ components in the Fe $2 p$ spectra. The binding energy (BE) and chemical state were listed in Table 5. As seen the binding energies are centered at 705.9, 709.1 and $711.8 \mathrm{eV}$, which can be attributed to $\mathrm{Fe}$ (II)-S, $\mathrm{Fe}$ (III)-O and Fe (II)-S, respectively. ${ }^{12)}$ 
The surface properties of the oxygen element were analyzed by using XPS as shown in Fig. 6. As seen the binding energies are centered at $531.7 \mathrm{eV}$ which can be attributed to an $\mathrm{O}^{2-}$ species.

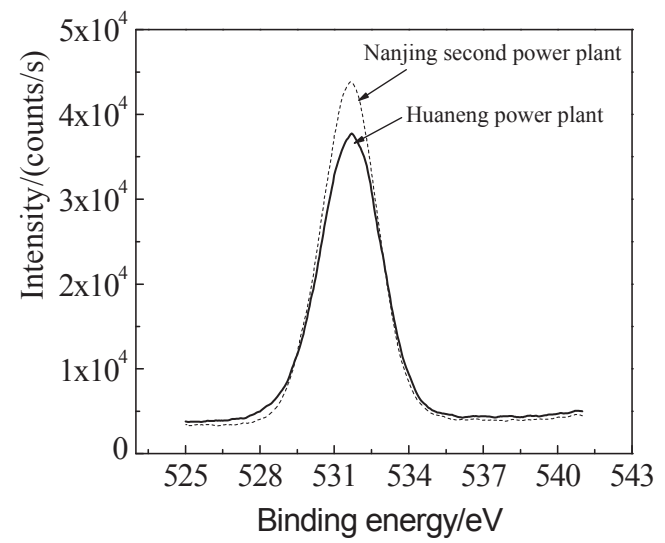

Fig. 6 XPS spectra of oxygen element on cement surface.

\subsection{Mössbauer analysis}

Figure 7 showed that the Mössbauer spectra of the fly ash contained superimposed single peak, doublets and sextets. Spectra 1, 2 contained doublets peaks and Spectra 3, 4 contained sextet's peaks. It was suggested that there were four kinds of iron form in fly ash at least, and Mössbauer parameters were shown as in Table 6 .

Table 6 showed that fly ash contained maghemite $(\alpha$ $\left.\mathrm{Fe}_{2} \mathrm{O}_{3}\right)$, magnetite $\left(\mathrm{Fe}_{3} \mathrm{O}_{4}\right)$ and $\mathrm{Fe}^{3+}$-mullite where the $\mathrm{Fe}$ mullite and maghemite were present as major phase. Haematite $\left(\alpha-\mathrm{Fe}_{2} \mathrm{O}_{3}\right)$, magnetite $\left(\mathrm{Fe}_{3} \mathrm{O}_{4}\right)$ have internal magnetic field, which can contribute to the magnetic behavior. ${ }^{13,14)}$ According to Mössbauer theory, $\mathrm{Fe}^{2+} 3 \mathrm{~d}^{6}$ has one more outer electron than $3 \mathrm{~d}^{5}$ of $\mathrm{Fe}^{3+}$, so the $\delta$ of $\mathrm{Fe}^{2+}$ is more than $\delta$ of $\mathrm{Fe}^{3+}$, which is $1.14 \mathrm{~mm} / \mathrm{s}$ and $0.44 \mathrm{~mm} / \mathrm{s}$ respectively. Based on the theory, the state of iron is easy to be identified.

\subsection{Electromagnetic parameters testing}

Electromagnetic parameters tested at the frequency range of $1-18 \mathrm{GHz}$ were shown in Fig. 8 .

Table 5 Qualitative and quantitative XPS results of state of iron on fly ash surface.

\begin{tabular}{|c|c|c|c|c|c|c|}
\hline & \multicolumn{3}{|c|}{ Nanjing second power plant } & \multicolumn{3}{|c|}{ Huaneng power plant } \\
\hline Binding energies /eV & 705.9 & 709.1 & 711.8 & 708.2 & 710.8 & 712.3 \\
\hline Chemical state & $\mathrm{Fe}(\mathrm{II})-\mathrm{S}$ & $\mathrm{Fe}(\mathrm{II})-\mathrm{O}$ & $\begin{array}{l}\mathrm{FeOOH} \\
\mathrm{Fe}(\text { II })-\mathrm{S}\end{array}$ & $\mathrm{Fe}(\mathrm{II})-\mathrm{S}$ & $\begin{array}{c}\mathrm{Fe}(\mathrm{III})-\mathrm{O} \\
\mathrm{Fe}(\mathrm{II})\end{array}$ & $\mathrm{Fe}(\mathrm{II})-\mathrm{S}$ \\
\hline
\end{tabular}
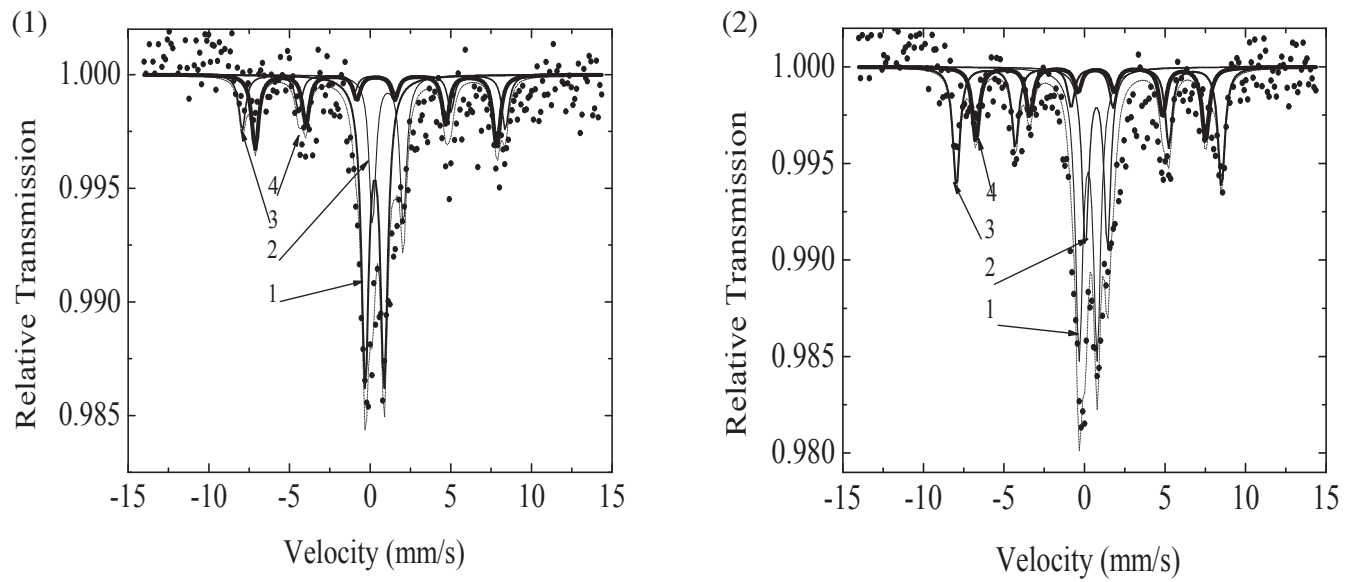

Fig. 7 Mössbauer spectra of fly ash. (1) Nanjing second power plant. (2) Huaneng power plant.

Table 6 Mössbauer parameters of fly ash.

\begin{tabular}{ccccccc}
\hline & $\begin{array}{c}\text { Area } \\
(\%)\end{array}$ & $\begin{array}{c}\mathrm{IS}(\delta) \\
(\mathrm{mm} / \mathrm{s})\end{array}$ & $\begin{array}{c}\mathrm{QS}(\Delta) \\
(\mathrm{mm} / \mathrm{s})\end{array}$ & $\begin{array}{c}\mathrm{Hhf} \\
(\mathrm{Koe})\end{array}$ & $\begin{array}{c}\Gamma \\
(\mathrm{mm} / \mathrm{s})\end{array}$ & Assignment \\
\hline \multirow{2}{*}{$\begin{array}{c}\text { Nanjing } \\
\text { second }\end{array}$} & $43.8 \%$ & $0.28(8)$ & $1.1(8)$ & - & $0.54(0)$ & $\mathrm{Fe}^{3+}$-mullite \\
power plant & $19.7 \%$ & $1.1(1)$ & $1.9(0)$ & - & $0.49(2)$ & $\mathrm{Pyrite}\left(\mathrm{FeS}_{2}\right)$ \\
& $21.3 \%$ & $0.26(2)$ & $-0.0(6)$ & $505 .(7)$ & $0.51(3)$ & Haematite $\left(\alpha-\mathrm{Fe}_{2} \mathrm{O}_{3}\right)$ \\
& $34.3 \%$ & $0.36(7)$ & $0.0(1)$ & $464 .(5)$ & $0.53(4)$ & Magnitite $\left(\mathrm{Fe}_{3} \mathrm{O}_{4}\right)$ \\
\hline \multirow{3}{*}{ Huaneng } & $19.8 \%$ & $0.74(1)$ & $1.37(0)$ & - & $0.49(2)$ & $\mathrm{Fe}^{3+}$-mullite \\
power plant $\left(\mathrm{FeS}_{2}\right)$ \\
& $28.0 \%$ & $0.37(4)$ & $-0.19(5)$ & $510 .(5)$ & $0.51(3)$ & Haematite $\left(\alpha-\mathrm{Fe}_{2} \mathrm{O}_{3}\right)$ \\
& $17.9 \%$ & $0.55(8)$ & $-0.34(0)$ & $442 .(3)$ & $0.53(4)$ & Magnitite $\left(\mathrm{Fe}_{3} \mathrm{O}_{4}\right)$ \\
\hline
\end{tabular}



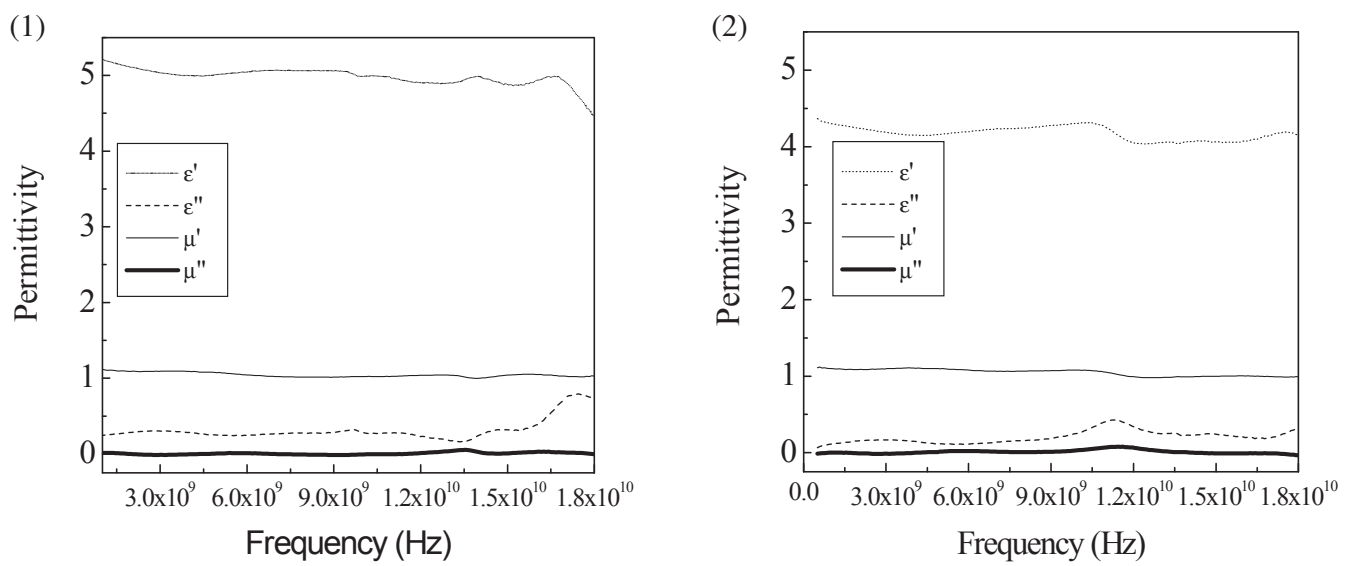

Fig. 8 The electromagnetic parameters of fly ash at frequency of $1 \sim 18 \mathrm{GHz}$. (1) Nanjing second power plant. (2) Huaneng power plant.

Table 7 Electromagnetic parameters of Nanjing second power plant fly ash.

\begin{tabular}{ccccccc}
\hline Frequency/GHz & $\varepsilon^{\prime}$ & $\varepsilon^{\prime \prime}$ & $\tan \delta_{\mathrm{e}}$ & $\mu^{\prime}$ & $\mu^{\prime \prime}$ & $\tan \delta_{\mathrm{m}}$ \\
\hline 1 & 5.22 & 0.24 & 0.046 & 1.11 & 0.015 & 0.014 \\
2 & 5.10 & 0.29 & 0.057 & 1.09 & -0.002 & -0.002 \\
3 & 5.03 & 0.30 & 0.060 & 1.09 & -0.01 & -0.009 \\
4 & 5.00 & 0.28 & 0.056 & 1.09 & -0.004 & -0.004 \\
5 & 5.01 & 0.25 & 0.050 & 1.07 & 0.008 & 0.008 \\
6 & 5.04 & 0.25 & 0.050 & 1.04 & 0.01 & 0.010 \\
7 & 5.07 & 0.27 & 0.053 & 1.02 & 0 & 0 \\
8 & 5.06 & 0.28 & 0.055 & 1.02 & -0.01 & -0.010 \\
9 & 5.06 & 0.29 & 0.057 & 1.02 & -0.01 & -0.010 \\
10 & 5.00 & 0.27 & 0.054 & 1.02 & -0.01 & -0.010 \\
11 & 4.97 & 0.28 & 0.056 & 1.03 & -0.002 & -0.002 \\
12 & 4.90 & 0.23 & 0.047 & 1.04 & 0.01 & 0.010 \\
13 & 4.90 & 0.18 & 0.037 & 1.04 & 0.04 & 0.038 \\
14 & 4.96 & 0.27 & 0.054 & 1.00 & 0.02 & 0.020 \\
15 & 4.87 & 0.32 & 0.066 & 1.04 & 0.01 & 0.010 \\
16 & 4.94 & 0.39 & 0.079 & 1.05 & 0.03 & 0.029 \\
17 & 4.87 & 0.77 & 0.159 & 1.02 & 0.02 & 0.019 \\
18 & 4.47 & 0.73 & 0.165 & 1.03 & 0.002 & 0.002 \\
\hline
\end{tabular}

From Fig. 8(1), we knew that the real part of complex permittivity $\varepsilon^{\prime}$ of electric loss was near 5 , and the imaginary part of complex permittivity $\varepsilon^{\prime \prime}$ had one notable peak at the frequency of $18 \mathrm{GHz} ; \mu^{\prime}$ of magnetic loss was more than 1 , and $\mu^{\prime \prime}$ nearly equals 0 . From Fig. 8(2), we knew that $\varepsilon^{\prime}$ of electric loss was near 4 , and $\varepsilon^{\prime \prime}$ had two notable peaks at the frequency of $11-12 \mathrm{GHz}$ and $18 \mathrm{GHz}$ and $\mu^{\prime}$ of magnetic loss was more than 1 , and $\mu^{\prime \prime}$ nearly equals 0 . Consequently, electric loss of fly ash of Nanjing second power plant was more than of Huaneng power plant which were consistent with the result in Table 3 that content of $\mathrm{Fe}_{2} \mathrm{O}_{3}$ was only about the half of carbon.

Electric loss tangent and magnetic loss tangent are token as $\tan \delta$ which are calculated by eq. (1). The total electromagnetic loss is the sum of $\tan \delta_{\mathrm{e}}$ and $\tan \delta_{\mathrm{m}}$.

$$
\tan \delta_{\mathrm{e}}=\varepsilon^{\prime \prime} / \varepsilon^{\prime} \quad \tan \delta_{\mathrm{m}}=\mu^{\prime \prime} / \mu^{\prime}
$$

The calculated results of two samples were shown in Table 7 and Table 8 respectively.

As shown in Table 7, electric loss tangent $\tan \delta_{\mathrm{e}}$ reached maximum at the frequency of $17-18 \mathrm{GHz}$ but magnetic loss tangent $\tan \delta_{\mathrm{m}}$ reached maximum at $13 \mathrm{GHz}$, and $\tan \delta_{\mathrm{e}}$ were $2 \sim 5$ times more than $\tan \delta_{\mathrm{m}}$, which have indicated that fly ash was electric attenuation absorbent more than magnetic
Table 8 Electromagnetic parameters of Huaneng power plant fly ash.

\begin{tabular}{ccccccc}
\hline Frequency $/ \mathrm{GHz}$ & $\varepsilon^{\prime}$ & $\varepsilon^{\prime \prime}$ & $\tan \delta_{\mathrm{e}}$ & $\mu^{\prime}$ & $\mu^{\prime \prime}$ & $\tan \delta_{\mathrm{m}}$ \\
\hline 1 & 4.30 & 0.11 & 0.026 & 1.10 & 0 & 0 \\
2 & 4.24 & 0.15 & 0.035 & 1.09 & -0.009 & -0.009 \\
3 & 4.18 & 0.17 & 0.041 & 1.10 & -0.014 & 0.013 \\
4 & 4.15 & 0.15 & 0.036 & 1.11 & -0.002 & 0.002 \\
5 & 4.17 & 0.11 & 0.026 & 1.10 & 0.013 & 0.012 \\
6 & 4.20 & 0.11 & 0.026 & 1.08 & 0.02 & 0.019 \\
7 & 4.23 & 0.14 & 0.033 & 1.06 & 0.012 & 0.011 \\
8 & 4.25 & 0.16 & 0.038 & 1.07 & 0.007 & 0.007 \\
9 & 4.28 & 0.19 & 0.044 & 1.07 & 0.011 & 0.010 \\
10 & 4.31 & 0.27 & 0.063 & 1.08 & 0.036 & 0.033 \\
11 & 4.25 & 0.41 & 0.097 & 1.05 & 0.067 & 0.064 \\
12 & 4.05 & 0.34 & 0.084 & 0.99 & 0.061 & 0.062 \\
13 & 4.05 & 0.25 & 0.062 & 0.98 & 0.022 & 0.022 \\
14 & 4.07 & 0.23 & 0.057 & 0.99 & 0.003 & 0.003 \\
15 & 4.06 & 0.24 & 0.059 & 1.00 & -0.008 & 0.008 \\
16 & 4.07 & 0.19 & 0.047 & 1.00 & -0.007 & 0.007 \\
17 & 4.16 & 0.20 & 0.048 & 0.99 & -0.010 & 0.010 \\
18 & 4.16 & 0.32 & 0.077 & 0.99 & -0.034 & 0.034 \\
\hline
\end{tabular}

attenuation absorbent which were consistent with the content of $\mathrm{Fe}_{2} \mathrm{O}_{3}$ and carbon in Table 3 .

As shown in Table 8, electric loss tangent $\tan \delta_{\mathrm{e}}$ of Huaneng power plant fly ash reached maximum at the frequency of $18 \mathrm{GHz}$ but the value was only half of Nanjing second power plant fly ash. Magnetic loss tangent $\tan \delta_{\mathrm{m}}$ of Huaneng power plant fly ash was as same as of Nanjing second power plant fly ash, which was consistent with the content of $\mathrm{Fe}_{2} \mathrm{O}_{3}$ and carbon in Table 3. Because carbon powder and $\mathrm{FeO}$ are electric attenuation absorbents, which have higher electric loss tangent and the electromagnetic energy is mainly attenuated as a resistor. ${ }^{15)}$

In conclusion, it was clear that electric loss was more than magnetic loss for fly ash and the electromagnetic waveabsorbing property of type III was slightly more than of type I except 11-12 GHz.

According to the electromagnetic theory, the reflection coefficient for coated single-layer electromagnetic microwave absorbing materials is the function of real and imaginary part of complex permittivity and complex permeability, frequency (f) and thickness (d), which can be denoted as eq. (2). ${ }^{16)}$

$$
R=20 \lg \left|\frac{\sqrt{\frac{\mu_{r}}{\varepsilon_{r}}} \tanh \left[j(2 \pi f d / c) \sqrt{\mu_{r} \varepsilon_{r}}\right]-1 \mid}{\sqrt{\frac{\mu_{r}}{\varepsilon_{r}}} \tanh \left[j(2 \pi f d / c) \sqrt{\mu_{r} \varepsilon_{r}}\right]+1}\right|
$$



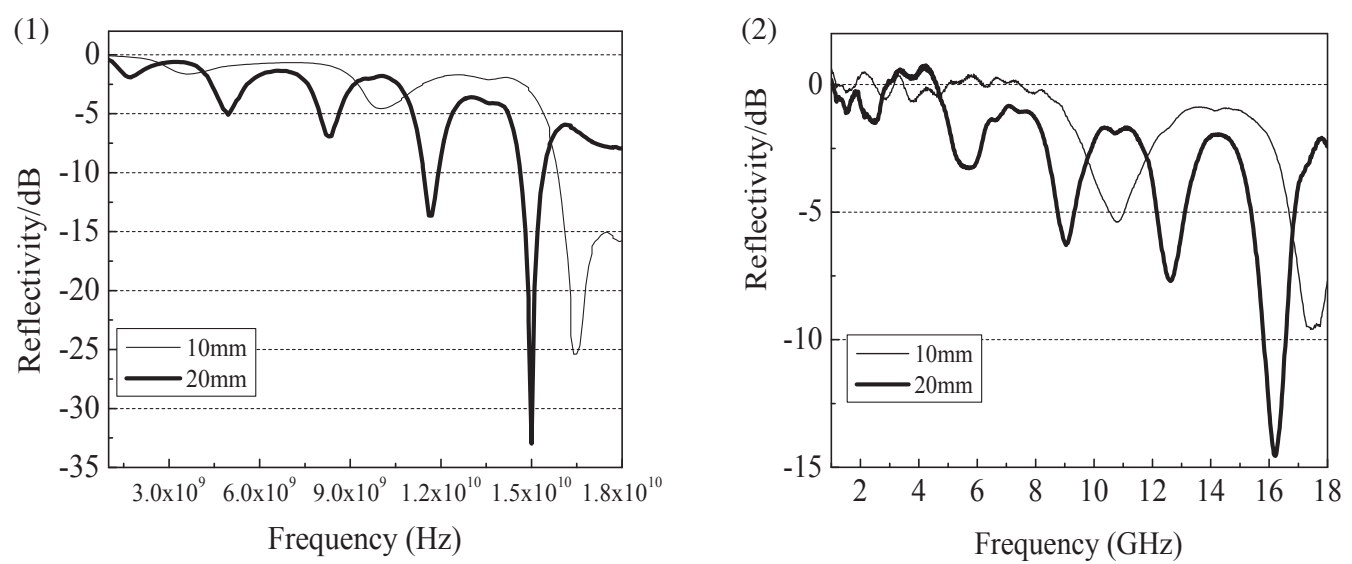

Fig. 9 Reflectivity of epoxy-based fly ash of Nanjing second power plant. (1) Calculated reflectivity. (2) Experimental reflectivity.

Where, $f$ and $d$ are the frequency of the electromagnetic wave and the thickness of the materials respectively, $c$ is the speed of light, $\pi$ is the constant, $\varepsilon_{r}$ and $\mu_{r}$ are the permittivity and permeability respectively, $j$ is the imaginary unit.

Based on the electromagnetic parameters in Fig. 8(1), the theoretical reflectivity computed by using formula $(2)^{17)}$ was shown as in Fig. 9(1), which were similar with experimental value shown as in Fig. 9(2).

\subsection{Reflectivity testing}

\subsubsection{Reflectivity of fly ash}

The absorbing wave properties of fly ash (Nanjing second power plant) were shown as in Fig. 9(2). There were several absorbing-wave peaks at the frequency of $1-18 \mathrm{GHz}$, and the biggest absorption reached $14.5 \mathrm{~dB}$ at $16 \mathrm{GHz}$ which were consistent with the electromagnetic parameters in Fig. 8(1); at the same time, absorbing effectiveness increased with the increase of sample thickness. In the high frequency, $\mathrm{Fe}_{2} \mathrm{O}_{3}$ have higher permeability, which can absorb electromagnetism wave by domain wall resonance and natural resonance. ${ }^{18,19)}$ On the other hand, Type III fly ash contains obvious unburned carbon, when electromagnetic wave penetrates into carbon porous or layer structure, which can cause loss of electromagnetic wave energy by multi-reflections, damping vibration equivalent to a bipolar and conductive network or electron-tunneling conduction. ${ }^{20)}$

According to the electromagnetic wave theory, when the thickness of the specimen is equal to a quarter of wavelength or it's odd times, the reflection waves from the two surfaces of specimen will interference, which can weaken the reflection wave energy. And with the increase of frequency, the interference peak will appear in turn. When the specimen thickness and the wavelength satisfy eq. (3), the interference happens.

$$
d=(2 n+1) \frac{\lambda_{0}}{4 \sqrt{\varepsilon_{r} \mu_{r}}}
$$

where: $d$ is the specimen thickness; $\lambda_{0}$ is the incident electromagnetic wavelength in vacuum; $\varepsilon$ and $\mu$ are the permittivity and permeability respectively.

Taken the largest peak at the frequency of $16.2 \mathrm{GHz}$ and $18 \mathrm{GHz}$ as the initial condition of $20 \mathrm{~mm}$ sample and $10 \mathrm{~mm}$ sample respectively, the several calculated interference peak
Table 9 The sites of the calculated interference peaks.

\begin{tabular}{ccccccccc}
\hline $\mathrm{d} / \mathrm{mm}$ & 20 & 20 & 20 & 20 & 20 & 10 & 10 & 10 \\
\hline $\mathrm{n}$ & 0 & 1 & 2 & 3 & 4 & 0 & 1 & 2 \\
Frequency $/ \mathbf{G H z}$ & 1.8 & 5.4 & 9.0 & 12.6 & 16.2 & 3.6 & 10.8 & 18 \\
\hline
\end{tabular}

sites were listed in Table 9, which matched very well with the peaks in Fig. 9(2). Thus the several peaks in Fig. 9 are inferred as the interference peaks.

3.6.2 Reflectivity of fly ash based on cement

Reflectivity of cement-based Type III fly ash (Nanjing second power plant) cured for 3 months were tested as shown in Fig. 10.

The absorbing wave properties of mortar (with $10 \%$ fly ash) were more than of hydrated cement (with $13 \%$ fly ash), which were similar with experimental value shown as in Fig. 9(2). The absorption of mortar in $10 \sim 18 \mathrm{GHz}$ frequency range were all over $6 \mathrm{~dB}$. As the main components of the standard sand, $\mathrm{SiO}_{2}$ has low dielectric constant, which can improve the free space impedance matching performance, thus increase the wave absorption performance.

\section{Conclusions}

From the results and discussion mentioned above, the following generalized conclusions can be drawn:

(1) Mineralogical phase and chemical composition electromagnetic properties of two samples are nearly the same. Fly ash exhibits electromagnetic wave absorbing property, due to porous or layer structure, carbon powder and iron oxide. In general electromagnetic wave-absorbing property of type III fly ash is slightly more than of type I fly ash.

(2) Fly ash contains maghemite $\left(\alpha-\mathrm{Fe}_{2} \mathrm{O}_{3}\right)$, magnetite $\left(\mathrm{Fe}_{3} \mathrm{O}_{4}\right)$ and $\mathrm{Fe}^{3+}$-mullite where the Fe-mullite and maghemite are present as major phase. Haematite $(\alpha-$ $\left.\mathrm{Fe}_{2} \mathrm{O}_{3}\right)$, magnetite $\left(\mathrm{Fe}_{3} \mathrm{O}_{4}\right)$ have internal magnetic field, which can contribute to the magnetic behavior. Electric loss tangent $\tan \delta_{\mathrm{e}}$ are 2 2 times than magnetic loss tangent $\tan \delta_{\mathrm{m}}$, which mean that fly ash are electric attenuation absorbent more than magnetic attenuation absorbent. 

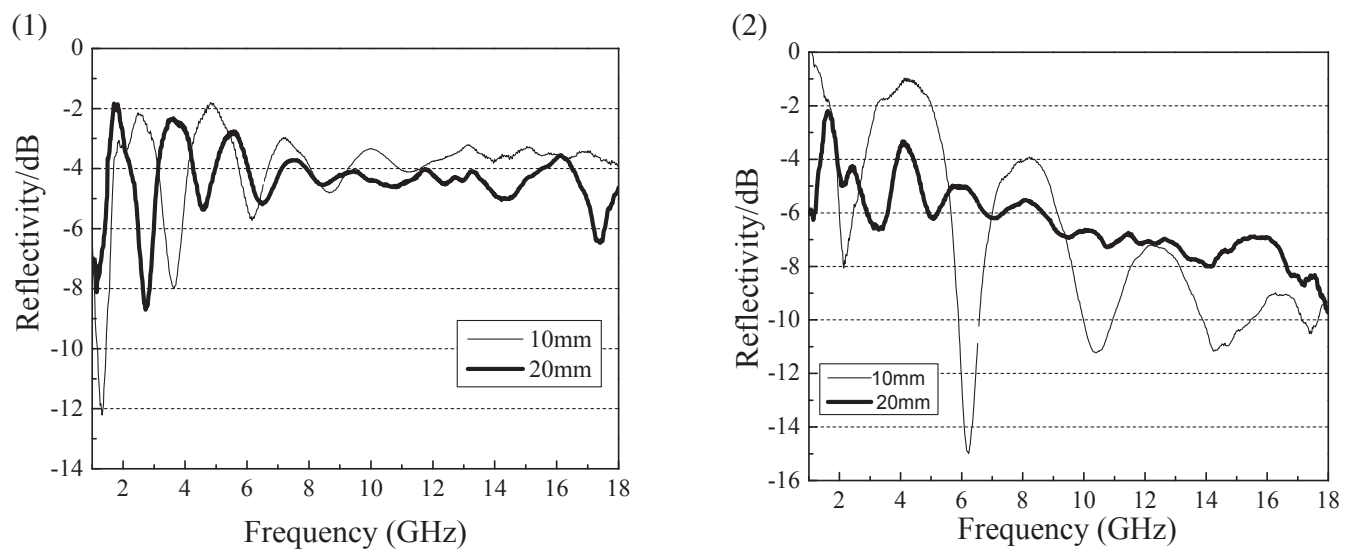

Fig. 10 Reflectivity of cement-based fly ash. (1) Hydrated cement. (2) Mortar.

(3) There are several absorbing-wave interference peaks at the frequency of $1-18 \mathrm{GHz}$, and the biggest absorption reaches $14.5 \mathrm{~dB}$ at $16 \mathrm{GHz}$ at the thickness of $20 \mathrm{~mm}$.

(4) The absorbing wave property of mortar with $10 \%$ type III fly ash is more than of hydrated cement with $13 \%$ type III fly ash, whose absorption is over $6 \mathrm{~dB}$ in $10 \sim 18 \mathrm{GHz}$ frequency range.

\section{Acknowledgements}

The investigation was funded by Pre-Research Fund of PLA University of Science and Technology (20140327) and supported by Ministry of Housing and Urban-Rural Development of the People's Republic of China (2008-K4-6). Authors thank Dr. Yongbao Feng for Calculation of reflectivity.

\section{REFERENCES}

1) D.Z. Cao, E. Selic and J.D. Herbell: J. Zhejiang Univ. Sci. A 9 (2008) 681-687.

2) C. Song, D.F. Xu, C.J. Jiang, Y. Teng, Z. Sun, H. Xu and L.S. An: J. Therm. Anal. Calorim. 116 (2014) 1279-1284.

3) X.S. Wang: Environ. Earth Sci. 71 (2014) 1673-1681.

4) O.A. Bajukov, N.N. Anshits, M.I. Petrova, A.D. Balaev and A.G. Anshits: Mater. Chem. Phys. 114 (2009) 495-503.
5) K. Hasezaki, A. Nakashita, G. Kaneko and H. Kakuda: Mater. Trans. 48 (2007) 3062-3065.

6) F. Moglie, D. Micheli, S. Laurenzi, M. Marchetti and V. Mariani Primiani: Carbon 50 (2012) 1972-1980.

7) A. Mofarrah, T. Husain and C. Bottaro: Int. J. Environ. Sci. Technol. 11 (2014) 159-168.

8) B.Y. Li, Y.P. Duan and S.H. Liu: Constr. Build. Mater. 27 (2012) 184188.

9) B.G. Ma, M. Qi, J. Peng and Z.J. Li: Environ. Int. 25 (1999) 423-432.

10) Y.B. Feng, T. Qiu, X.Y. Li and C.Y. Shen: J. Wuhan Univ. Technol. 22 (2007) 266-270.

11) Z. Lu, M.M. Maroto-Valer and H.H. Schobert: Fuel 87 (2008) 25982605.

12) J.F. Moulder, W.F. Stickle, P.E. Sobol and K.D. Bomben: Handbook of X-ray Photoelectron Spectroscopy, (Perkin Elmer Corp., Physical Electronics, Inc., USA., 1992).

13) Y. Maeda, S. Sugimoto, D. Book, H. Ota, M. Kimura, H. Nakamura, T. Kagotani and M. Homma: Mater. Trans. 41 (2000) 567-570.

14) F. Reyes Caballero, S.A.M. Ovalle and M.M. Gutińrrez: Hyperfine Interact. 232 (2015) 141-148.

15) P.J. Tumidajski: Cement Concr. Res. 35 (2005) 614-615.

16) Y.Q. Yang, S.H. Qi and J.N. Wang: J. Alloys Compd. 520 (2012) 114121.

17) Y.B. Feng and T. Qiu: Journal of Nanjing University of Aeronautics \& Astronautics 37 (2005) 232-235.

18) J. Cao and D.D.L. Chung: Cement Concr. Res. 34 (2004) 1889-1892.

19) P.J. Bora, K.J. Vinoy, P.C. Ramamurthy, Kishore and G. Madras: Electron. Mater. Lett. 12 (2016) 603-609.

20) H.Y. Liu, H.Z. Tan, Q. Gao and T.M. Xu: Fuel 89 (2010) 3352-3357. 